\title{
Commentary: POEM: Provision of effective management (through collaboration)
}

\author{
Virginia R. Litle, MD
}

In the past decade, surgeons have been inundated with presentations using large database studies-SEER (Surveillance, Epidemiology, and End Results), NCDB (National Cancer Database), STS (Society of Thoracic Surgeons)alphabet soup indeed. The value of such work is the generation of hypotheses for a deeper dive with clinical trials or detailed investigations. The predominant limitation cited frequently is the lack of granularity in the data. Another is the inability to address questions about less-common diseases. With lack of granularity clinically, we have difficulty knowing what to do with the authors' conclusions. For some diseases, collaborative groups like the Worldwide Esophageal Cancer Collaboration $^{1,2}$ and the International Thymic Malignancy Interest Group $^{3}$ among others have assembled working groups and built databases so meaningful results can create improvements in staging and clinical management.

Achalasia, with an incidence of $\sim 1$ in 100,000 adults per year and a rising prevalence, ${ }^{4}$ is an example of a disease for which a multi-institutional collaboration would facilitate research. It is remarkable that Sudarshan and colleagues ${ }^{5}$ can provide a robust, single-institution study of provision of effective management on patients with type III achalasia. The sample is drawn from an institutional database of 518 patients with achalasia collected over a 5-year period. Only Inoue and colleagues ${ }^{6}$ can produce similar-sized studies about provision of effective management. What makes this singleinstitution study robust? And what can others learn from this example? Collaboration within the institution and a detailed dataset. The authors cross disciplines in a

\footnotetext{
From the Division of Thoracic Surgery, Department of Surgery, Boston University School of Medicine, Boston, Mass.

Disclosures: The author reported no conflicts of interest.

The Journal policy requires editors and reviewers to disclose conflicts of interest and to decline handling or reviewing manuscripts for which they may have a conflict of interest. The editors and reviewers of this article have no conflicts of interest.

Received for publication Feb 28, 2021; revisions received Feb 28, 2021; accepted for publication March 2, 2021; available ahead of print March 5, 2021.

Address for reprints: Virginia R. Litle, MD, Division of Thoracic Surgery, Department of Surgery, Boston University, 88 East Newton St, Collamore 7380, Boston, MA 02118 (E-mail: Virginia.litle@bmc.org).

J Thorac Cardiovasc Surg 2022;163:520-1

$0022-5223 / \$ 36.00$

Copyright (c) 2021 by The American Association for Thoracic Surgery

https://doi.org/10.1016/j.jtcvs.2021.03.002
}
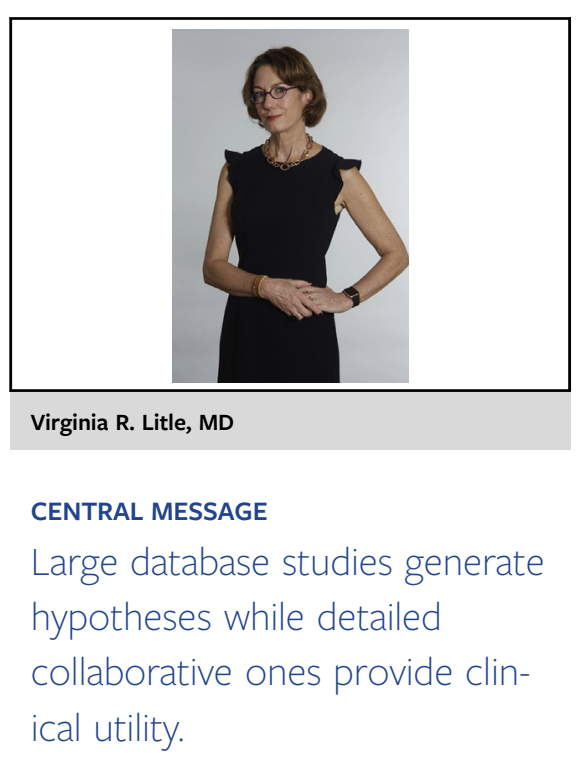

collaborative spirit. The achalasia database contains objective data including pre- and postmyotomy timed barium swallows, manometry measurements, and Eckardt scores, as well as procedural morbidity details. Where else do we find robust singleinstitution reports of uncommon diseases? Major cancer centers most often. Potential values of the single-institution studies including control of confounding interoperator or clinical care variability. The weakness of course is that it may not be easily applicable/transferable to other proceduralists.

Those are the strengths of single-center reports, and much of this takes resources not necessarily available to all. Resource-challenged institutions and those with small numbers must collaborate with others. Work the other direction-identify the clinical questions and then collaborate. An example relevant to the challenge of studying vulnerable populations to address health inequity is the need to form a consortium of surgeons and clinicians to create the database, ask the questions, and advance care. This takes money for coordinators, database managers, and statisticians in particular. As with clinical trials and biobanks, funding is available but proposals must start with specific aims, not with a flat-out request for money to set-up a database. The first steps then are to bring together those with their boots on the ground to brainstorm ideas, select a secure database like REDCap, and apply for support.

As the management of achalasia evolves, we look forward to future reports from this group at the Cleveland Clinic. Many lack the resources but can take a lesson from their playbook on how to make a difference for their patients with collaboration and attention to objective details. 


\section{References}

1. Rice TW, Ishwaran H, Blackstone EH, Hofstetter WL, Kelsen DP, AppersonHansen C, Worldwide Esophageal Cancer Collaboration Investigators. Recommendations for clinical staging (cTNM) of cancer of the esophagus and esophagogastric junction for the 8th edition AJCC/UICC staging manuals. Dis Esophagus. 2016;29:913-9.

2. Rice TW, Rusch VW, Apperson-Hansen C, Allen MS, Chen LQ, Hunter JG, et al. Worldwide esophageal cancer collaboration. Dis Esophagus. 2009;22:1-8.

3. Ruffini E, Fang W, Guerrera F, Huang J, Okumura M, Kim DK, et al, Staging and Prognostic Factors Committee, Staging and Prognostic Factors-Thymic Domain Subcommittee, Staging and Prognostic Factors Subcommittees, Members of the Advisory Boards. The International Association for the Study of Lung Cancer
Thymic Tumors Staging Project. The impact of the eighth edition of the Union for International Cancer Control and American Joint Committee on cancer TNM stage classification of thymic tumors. J Thorac Oncol. 2020;15:436-47.

4. Sadowski DC, Ackah F, Jiang B, Svenson LW. Achalasia: incidence, prevalence and survival. A population-based study. Neurogastroenterol Motil. 2010;22: e256-61.

5. Sudarshan M, Raja S, Adhikari S, Murthy S, Thota PN, Gabbard S, et al. Perora endoscopic myotomy provided effective palliation in type III achalasia. J Thorac Cardiovasc Surg. 2022;163:512-9.e1

6. Inoue H, Sato H, Ikeda H, Onimaru M, Sato C, Minami H, et al. Per-oral endoscopic myotomy: a series of 500 patients. J Am Coll Surg. 2015;221 256-64.

\section{See Article page 512.}

\section{Commentary: A nice beginning to this POEM, but the ending has yet to be written}

\author{
Michael Keirsey, MD, and Thomas Ng, MD
}

Achalasia is a primary disorder of esophageal motility involving the absence of esophageal peristalsis and impaired relaxation of the lower esophageal sphincter in response to swallowing. It can be subcategorized into 3 types based on manometric findings. Type III, the most difficult subtype of achalasia to treat, is characterized by premature or spastic esophageal contractions, which can extend much more proximal to the gastroesophageal junction than the other subtypes. Therefore, peroral endoscopic myotomy (POEM), which allows for a longer myotomy, may be the more effective treatment modality for type III achalasia symptoms compared with other therapies that target only the lower esophagus.

In their article in this month's Journal, Sudarshan and colleagues ${ }^{1}$ report a retrospective analysis of 36 patients undergoing POEM for type III achalasia at their tertiary care

\footnotetext{
From the Division of Thoracic Surgery, University of Tennessee Health Science Center, College of Medicine, Memphis, Tenn.

Disclosures: The authors reported no conflicts of interest.

The Journal policy requires editors and reviewers to disclose conflicts of interest and to decline handling or reviewing manuscripts for which they may have a conflict of interest. The editors and reviewers of this article have no conflicts of interest.

Received for publication March 5, 2021; revisions received March 5, 2021; accepted for publication March 8, 2021; available ahead of print March 11, 2021.

Address for reprints: Thomas Ng, MD, Division of Thoracic Surgery, University of Tennessee Health Science Center, College of Medicine, 1325 Eastmoreland Ave, Suite 460, Memphis, TN 38104 (E-mail: tng4@uthsc.edu).

J Thorac Cardiovasc Surg 2022;163:521-2

$0022-5223 / \$ 36.00$

Copyright (c) 2021 by The American Association for Thoracic Surgery

https://doi.org/10.1016/j.jtcvs.2021.03.026
}

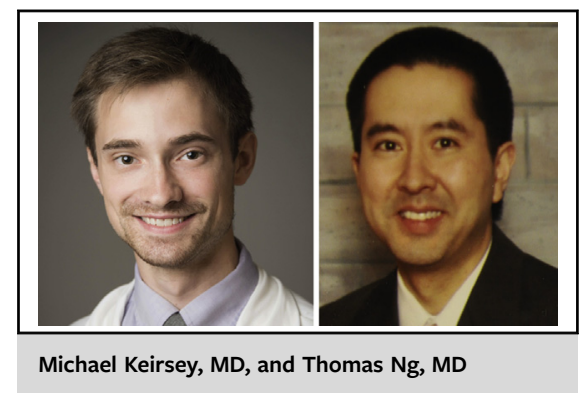

CENTRAL MESSAGE

POEM appears to be a safe and effective treatment for the symptoms of type III achalasia, but current data has yet to adequately address the longterm implications of the resultant reflux.

institution between 2014 and 2019. The median procedure time was 85 minutes, the median hospital length of stay was 1 day, and complications were few and not severe. At a 1-year follow-up, patients showed significant improvement in symptoms as measured by the Eckardt score, improvement in timed barium column height and width study, and improvement in lower esophageal sphincter (LES) integrated resting pressure (IRP). Overall, for the treatment of type III achalasia, POEM was successful, as defined by an Eckardt score of $\leq 3$, in $94 \%$ of the patients.

The authors then compared this POEM cohort with 35 patients who underwent laparoscopic Heller myotomy (LHM) with Dor fundoplication between 2006 and 2019 